\title{
Análise do número de desempregos formais no Rio Grande do Sul
}

\author{
JULIANA HAETINGER FURTADO, ${ }^{\mathrm{I}}$ \\ ADRIANO MENDONÇA SOUZA II \\ e RosELAINE RUVIARO ZANINI III
}

\section{Breve histórico e caracterização}

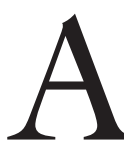

CRISE ATUAL que se estende em escala global é tema de discussão por diversos especialistas. Os resultados esperados por medidas de austeridade fiscal em curto, médio e longo prazos são incertos e preocupam todos os etores da economia. A situação reflete prejuízo imediato ao mercado de trabalho. Trabalhadores estão sendo demitidos em massa e a informalidade está ganhando espaço, obstruindo os direitos até então conquistados. A sociedade brasileira passa por um momento em que a estrutura, até então estável, tornou-se insegura com reflexos expressivamente desfavoráveis.

Nesse contexto, caracterizado por Antunes (2010) como um "processo de precarização estrutural do trabalho", tomado por flexibilizações que limitam os direitos dos trabalhadores e geram prejuízos drásticos, afetam-se não só os indivíduos atores desse cenário, mas toda a sociedade brasileira. A situação é histórica e marcada por particularidades ora positivas, ora adversas.

O advento do Plano Real, período que antecede o deste estudo, assinalou um cenário de abertura comercial, valorização de moeda estrangeira e elevadas taxas de juros que trouxeram por consequência redução de custos e aumento da produtividade, acarretando a diminuição drástica em postos de trabalho principalmente na indústria. Segundo Jornada (2004), no período entre 1994 e 2002 , no Rio Grande do Sul (RS), as implicações foram desde as restrições nas exportações, ampliação dos empregos informais, ao aumento significativo do PIB com desempenho médio maior que o nacional. No mesmo contexto, Accurso (2002) afirma que, no estado, entre 1990 e 1998, apenas o setor terciário ampliou suas vagas de emprego, enquanto nos setores primário e secundário essas foram reduzidas. Porém, esse panorama não evidenciou queda na produção desses dois setores que, em termos percentuais, evoluíram em 6,6\% e 3,8\%, respectivamente, contra apenas $0,3 \%$ do setor terciário.

A retomada do crescimento da economia brasileira, a partir dos anos 2000, não influenciou diretamente no aumento da participação do Produto Interno 
Bruto (PIB) do RS no PIB nacional. Em meados da década de 1970, o RS participava com aproximadamente $8,5 \%$ do PIB brasileiro e, atualmente, representa em torno de 6,36\% do PIB nacional. Destaca-se que, entre 2002 e 2011, o PIB nacional cresceu, em média, $3,8 \%$ ao ano, enquanto, no RS, esse crescimento foi aproximadamente $2,9 \%$. Todavia, observando o período compreendido entre 2007 e 2011, quando a população do RS expandiu-se de forma mais lenta que a nacional, o PIB per capita rio-grandense, apresentou-se maior que o nacional, $3,6 \%$ contra $3,1 \%$, tornando evidente que, para acompanhar o crescimento brasileiro, o RS pode apresentar um PIB menor desde que não haja expansão de sua população (Hoff; Lazzari, 2014).

Os mesmos autores colocam ainda que, considerando o crescimento setorial desde 2002, quando a economia do estado representava $7,22 \%$ do Valor Adicionado Bruto (VAB) e reduziu para 6,45\% em 2011, assim como ocorreu com os estados de São Paulo e Rio de Janeiro, o setor da Agropecuária foi o único que contribui positivamente no $\mathrm{VAB}$, com crescimento de $75,2 \%$ no RS contra 44,7\% no Brasil nesse período.

Em relação à oferta de emprego em todos os setores, consta no relatório sobre o mercado de trabalho no Rio Grande do Sul elaborado por Stein, Sulzbach e Bartels (2015), que a taxa de formalidade no setor privado no estado aumentou de $74,8 \%$, em 2002 , para $84,1 \%$, em 2013. Para os autores, essa taxa poderia ser maior no caso da inexistência do piso regional em algumas categorias. Do mesmo modo, o nível de formalidade no mercado de trabalho aumenta à medida que a economia tem desempenho positivo. Por outro lado, ao mesmo tempo que aumentam os desligamentos do emprego celetista, pode-se considerar o reflexo da decadência econômica no país ou no estado.

Em recente publicação do Cadastro Geral de Empregados e Desempregados (Caged), que sintetiza informações do comportamento do mercado de trabalho formal no Rio Grande do Sul, foi divulgado que, em maio de 2015, foram eliminados, no estado, 15.815 empregos celetistas. Entretanto, nos cinco primeiros meses deste ano, ocorreu um acréscimo de $0,05 \%$ nas vagas, o que representa 1.335 novos postos de trabalho. No período de maio de 2014 até maio de 2015 contabilizou-se queda de 1,13\% no nível de emprego, o que significa menos 30.662 postos de trabalho, aferindo os oito setores da economia. Considerando os municípios do RS que fazem parte do banco de dados do Ministério do Trabalho e Emprego (MTE), no caso, aqueles com mais de 30 mil habitantes, dos 71 apenas oito municípios apresentaram saldo positivo ou nulo no que se refere aos postos de emprego formal em maio de 2015.

Assim, no intuito de verificar a situação do desemprego no estado do Rio Grande do Sul, este artigo tem por objetivo apresentar algumas estatísticas sobre os desligamentos no mercado de trabalho formal, em parâmetro microeconômico, evidenciando a importância do levantamento de dados disponibilizados pelo Caged juntamente com o Ministério do Trabalho e Emprego (MTE). 


\section{Procedimentos metodológicos}

Para avaliar o comportamento dos desligamentos do emprego formal no Rio Grande do Sul por setor de atividade econômica e, para a realização deste, foi considerada a série histórica mensal de dados desde janeiro de 2004 a dezembro de 2014, disponibilizadas junto ao Ministério do Trabalho e Emprego.

O Ministério do Trabalho e Emprego disponibiliza um conjunto de tabelas que contém informações desagregadas segundo os setores econômicos do IBGE, classificadas por estados da Federação, principais regiões metropolitanas, municípios com mais de 10 mil habitantes para o estado de São Paulo e 30 mil habitantes para os demais estados conforme o último censo realizado. Os dados disponibilizados permitem obter informações em relação aos oito setores de atividade econômica (extrativa mineral, indústria de transformação, Serviços Industriais de Utilidade Pública - SIUP, construção civil, comércio, serviços, agropecuária e administração pública) para as 27 Unidades de Federação, para nove regiões metropolitanas e 1.102 municípios.

Inicialmente, neste estudo, foi realizada uma análise descritiva, de modo a encontrar os valores mínimos, máximos, média, desvio-padrão e coeficiente de variação para o número de desempregados relativo a cada setor em questão, bem como o valor total de admitidos e desligados e o respectivo saldo de empregos. Além disso, foram construídos os gráficos Box-Plot para elucidar melhor estas características descritivas.

A seguir, foi utilizado o teste de Shapiro-Wilk para verificar o ajuste dos dados à distribuição Normal. Para verificar se existe diferença significativa entre o número de desligados para todos os setores foi realizado o teste de Kruskal-Wallis.

Posteriormente, a série temporal foi dividida em dois períodos de 66 meses cada um (janeiro de 2004 - junho de 2009 e julho de 2009 - dezembro de 2014), e o teste U de Mann-Whitney foi realizado com o intuito de verificar se existe diferença significativa no número de desempregados quando se comparam os dois períodos. Finalizando, foi realizado um ajuste, por setor, por meio de modelo de regressão simples no tempo, para verificar se existe ou não tendência significativa no número de desempregados. Todos os testes foram realizados considerando-se um nível de $5 \%$ de significância e as análises estatísticas foram realizadas com o uso do software Statistica 9.1.

\section{Resultados - Panorama dos desligamentos no mercado de trabalho formal no Rio Grande do Sul}

O desemprego no mercado formal de trabalho no RS é caracterizado a seguir, no qual é possível observar a variação ocorrida em cada um dos setores: Extrativa Mineral, Indústria de Transformação, SIUP, Construção Civil, Comércio, Serviços, Agropecuária e Administração Pública.

No período compreendido entre janeiro de 2004 e dezembro de 2014, foram eliminados, no RS, 12.404.198 empregos celetistas, e o setor que apre- 
sentou maior número de pessoas desligadas foi de Indústria de Transformação, com 3.813.805 trabalhadores demitidos. O setor com menor participação foi o Extrativa Mineral com um total de 25.490 desligados.

O setor que apresentou maior variação relativa nos desligamentos durante os 132 meses analisados foi o da Administração Pública, com aproximadamente $52 \%$ de variação; e o setor com menor variação foi Indústria de Transformação, com aproximadamente $16 \%$. Todavia, o setor com maior número de desligamentos pontual foi o de Serviços, com um total de 43.884 pessoas demitidas, ocorrido em março de 2014.

Ainda, o setor que apresentou menor média $(193,11)$ de desligamentos foi Extrativa Mineral, e o setor com maior média $(28892,46)$ foi o de Indústria de Transformação. Os resultados mais detalhados podem ser observados na Tabela 1 .

Tabela 1 - Medidas descritivas do número de desligamentos no RS, por setor

\begin{tabular}{l|c|c|c|c|c}
\hline \multicolumn{1}{c|}{ Setores } & Média & Mínimo & Máximo & $\begin{array}{c}\text { Desvio } \\
\text { Padrão }\end{array}$ & $\begin{array}{c}\text { Coeficiente } \\
\text { Variação } \\
(\%)\end{array}$ \\
\hline Extrativa Mineral & 193,11 & 94,00 & 992,00 & 82,740 & 42,85 \\
\hline Ind. Transformação & $28.892,46$ & $19.648,00$ & $38.612,00$ & $4.718,65$ & 16,33 \\
\hline SIUP & 486,39 & 220,00 & 914,00 & 140,34 & 28,85 \\
\hline Construção Civil & $7.894,54$ & $4.233,00$ & $12.846,00$ & $2.716,79$ & 34,41 \\
\hline Comércio & $22.329,53$ & $12.425,00$ & $35.254,00$ & $6.444,24$ & 28,86 \\
\hline Serviços & $28.422,67$ & $15.929,00$ & $43.884,00$ & $8.200,13$ & 28,85 \\
\hline Administração & 316,81 & 115,00 & $1.054,00$ & 166,26 & 52,48 \\
\hline Pública & $5.435,69$ & $2.093,00$ & $10.915,00$ & $2.133,85$ & 39,26 \\
\hline Agropecuária & & & & & \\
\hline
\end{tabular}

Fonte: Elaborado pelo autor a partir de dados do MTE.

Nas Figuras l e 2 é possível visualizar algumas características descritivas de cada setor, como mediana e quartis. Verifica-se que, para os cinco setores da Figura 1, não se observa a presença de outliers ou valores extremos. 
Figura 1 - Box-plot para os setores: Indústria de Transformação, Construção Civil, Comércio, Serviço e Agropecuária

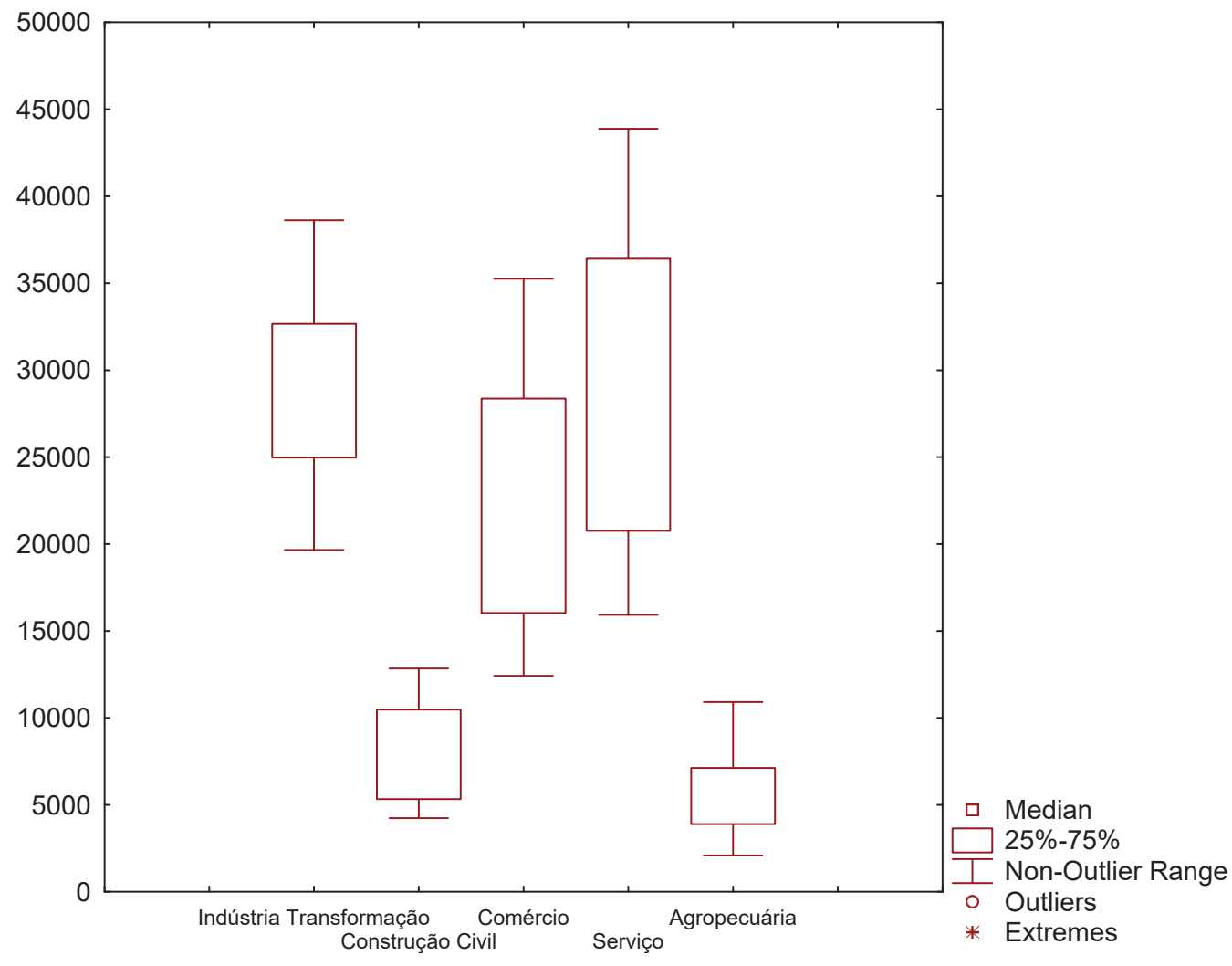

Fonte: Elaborado pelo autor a partir de dados do MTE.

Para os três setores considerados na Figura 2, observa-se, entretanto, a presença de outliers e/ou valores extremos. 
Figura 2 - Box-plot para os setores: Extrativa Mineral, SIUP e Administração Pública

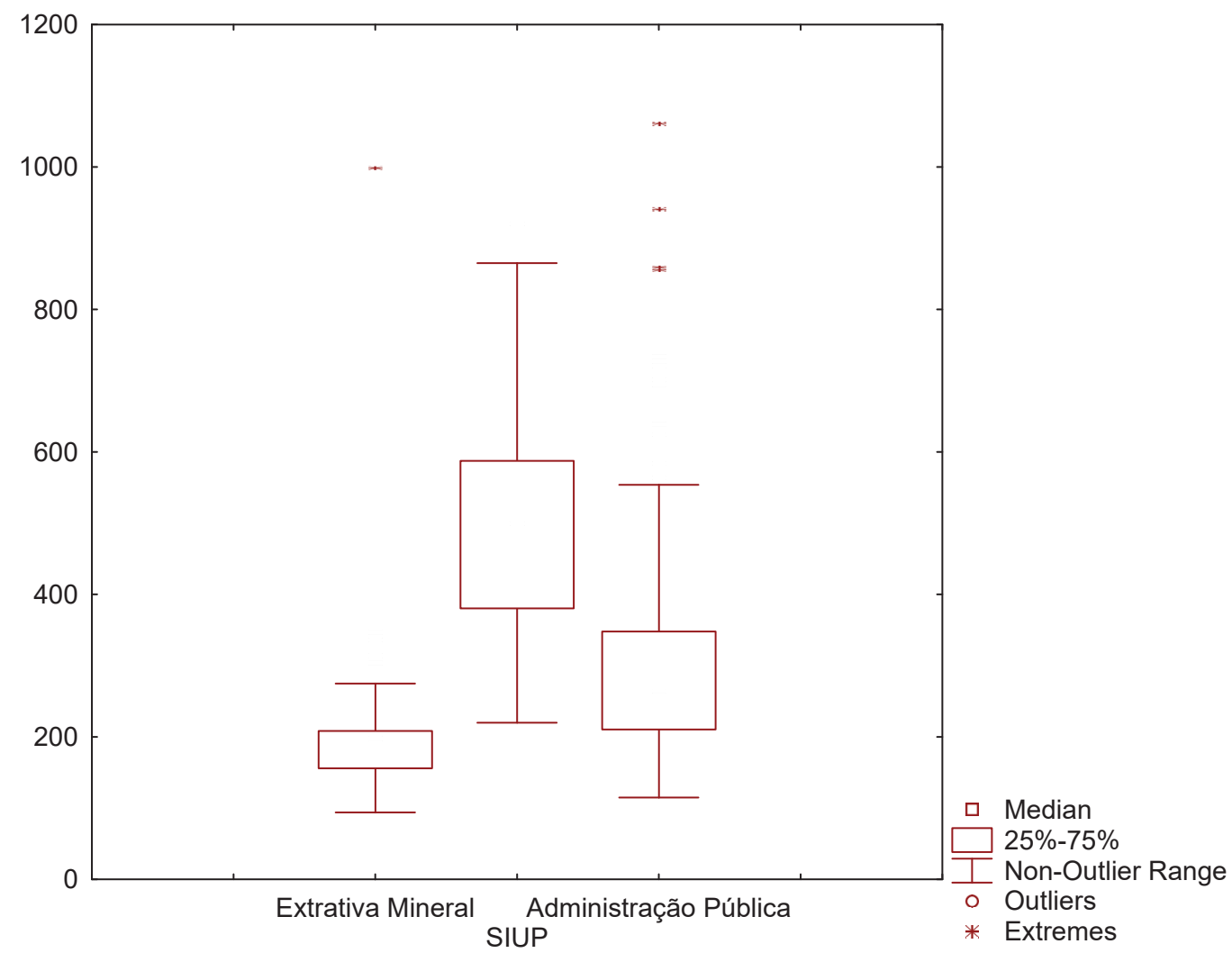

Fonte: Elaborado pelo autor a partir de dados do MTE.

A seguir, é apresentado o saldo de pessoas obtido entre o total de admitidos e o total de desligados no período de 132 meses em cada setor, de modo a comparar o setor que está em déficit ou não com o total de empregados celetistas. Segundo os dados do Caged é possível observar que a Administração Pública foi o único setor que apresentou um déficit, de 40 trabalhadores no período considerado (Tabela 2.). Vale lembrar que, durante o período, a população do RS aumentou e, consequentemente, se elevaram as necessidades desta população em relação à oferta de emprego em todos os setores. 
Tabela 2 - Número de pessoas admitidas, desligadas e saldo por setor, no RS

\begin{tabular}{l|c|c|c}
\hline \multicolumn{1}{c|}{ Setores } & Admitidos & Desligados & Saldo \\
\hline Extrativa Mineral & 28.317 & 25.490 & 2.827 \\
\hline Ind. Transformação & 3.969 .934 & 3.813 .805 & 156.129 \\
\hline SIUP & 71.032 & 64.203 & 6.829 \\
\hline Construção Civil & 1.104 .666 & 1.042 .079 & 62.587 \\
\hline Comércio & 3.216 .965 & 2.947 .498 & 269.467 \\
\hline Serviços & 4.134 .066 & 3.751 .793 & 382.273 \\
\hline Administração Pública & 41.779 & 41.819 & -40 \\
\hline Agropecuária & 723.071 & 717.511 & 5.560 \\
\hline
\end{tabular}

Fonte: Elaborado pelo autor a partir de dados do MTE.

Não foi observada diferença significativa quando se comparou o número de desligamentos ocorridos no período entre janeiro de 2004 e dezembro de 2014 para os setores Extrativo Mineral e Administração Pública $(\mathrm{p}=0,10)$, Indústria de Transformação e Comércio $(\mathrm{p}=0,13)$, Indústria de Transformação e Serviço $(\mathrm{p}=0,99)$, SIUP e Administração Pública $(\mathrm{p}=0,13)$, Construção Civil e Agropecuária $(\mathrm{p}=0,99)$ e entre os setores Comércio e Serviço $(\mathrm{p}=$ $0,527009)$. As comparações entre os outros setores apresentaram diferença significativa $(\mathrm{p}<0,05)$.

O pressuposto de normalidade para os dados da série, em cada setor, não foi atendido e, desse modo, por meio do teste não paramétrico $U$ de Mann-Whitney observou-se diferença significativa em relação ao número de pessoas desligadas, do primeiro para o segundo período, nos setores Extrativa Mineral $(\mathrm{p}<0,001)$, Indústria Transformação $(\mathrm{p}<0,001)$, SIUP $(\mathrm{p}<0,001)$, Construção Civil ( $\mathrm{p}<0,001)$, Comércio $(\mathrm{p}<0,001)$ e Serviço $(\mathrm{p}<0,001)$. Não foi encontrada diferença significativa para o setor Administração Pública $(\mathrm{p}=0,408)$ e para o setor Agropecuário $(\mathrm{p}=0,061)$.

Nas Figuras 3 e 4, é observada a série completa dos desligamentos do emprego celetista formal no RS no período compreendido entre janeiro de 2004 e dezembro de 2014, que, devido à amplitude dos valores, foram separados em dois gráficos distintos de modo a obter maior clareza em sua análise.

Pode-se observar, na Figura 3, a evolução do número de desempregados para cinco setores. Dentre esses setores, verificou-se que todos apresentaram tendência crescente significativa no número de desempregados: Indústria de Transformação $(\mathrm{p}<0,001)$, Construção Civil $(\mathrm{p}<0,001)$, Comércio $(\mathrm{p}<$ $0,001)$, Serviço $(\mathrm{p}<0,001)$ e Agropecuária $(\mathrm{p}=0,02)$. 
Figura 3 - Empregos celetistas formais eliminados no RS entre janeiro de 2004 e dezembro de 2014

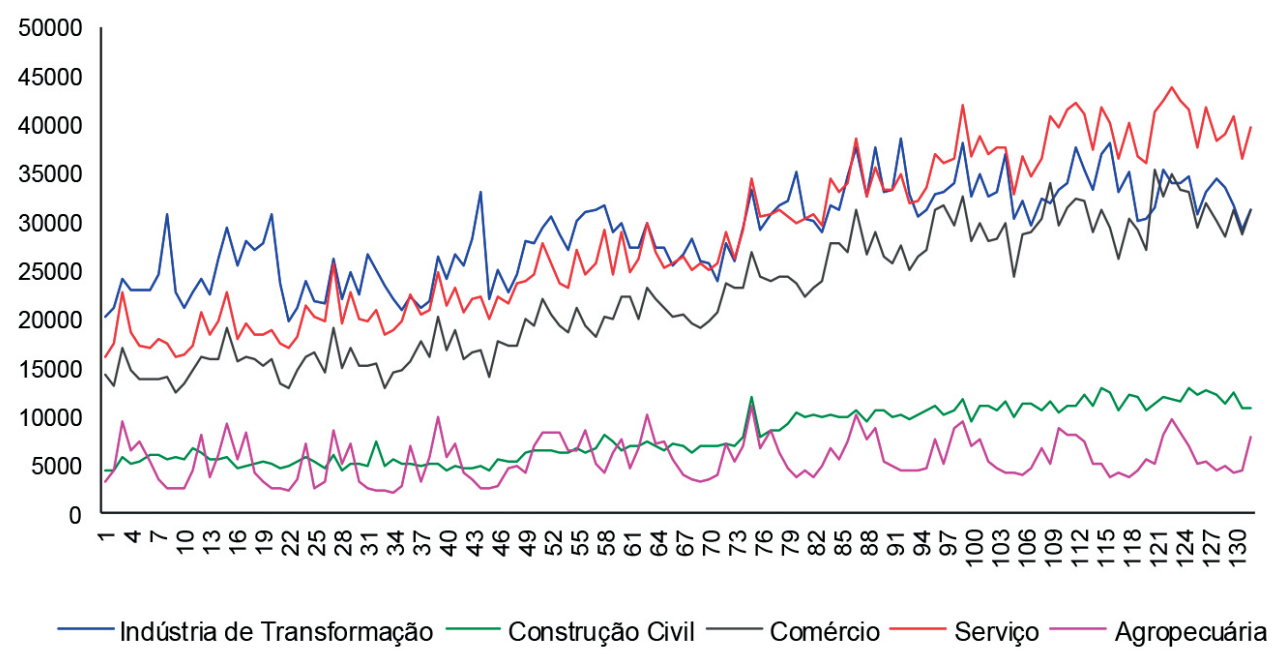

Fonte: Elaborado pelo autor a partir de dados do MTE.

Na Figura 4 é apresentado o comportamento dos setores Extrativa Mineral, SIUP e Administração Pública. Por meio da análise de regressão linear simples foi possível identificar os setores Extrativa Mineral e SIUP apresentaram tendência crescente significativa $(\mathrm{p}<0,001)$ para o número de desempregados no RS. O setor de Administração Pública não apresentou tendência significativa de $(\mathrm{p}=0,46)$.

Figura 4 - Empregos celetistas formais eliminados no RS entre janeiro de 2004 e dezembro de 2014

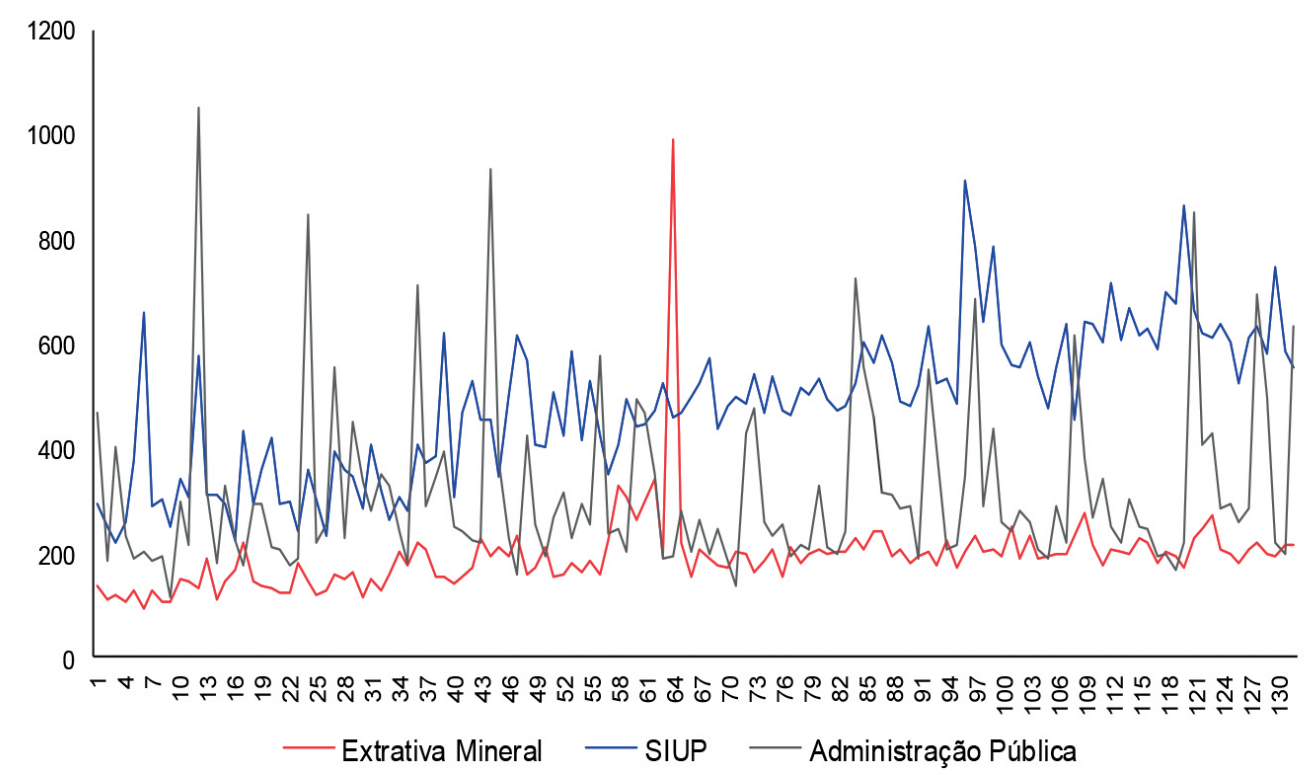

Fonte: Elaborado pelo autor a partir de dados do MTE. 
Não obstante, vale ressaltar que os setores que apresentaram maior coeficiente angular na reta de ajuste apresentaram, ao longo do tempo, um crescimento maior em seu número de desligamentos no emprego celetista formal no RS, e o setor com maior crescimento foi o de Serviços $(\alpha=202,69)$, seguido do Comércio $(\alpha=156,90)$. O setor que apresentou menor acréscimo foi Extrativa Mineral $(\alpha=0,6331)$, o que indica que o aumento foi mais modesto em relação aos demais.

\section{Análise dos resultados e discussão do desemprego em esfera nacional e estadual}

É possível observar, atualmente, que o poder público, em parâmetro macroeconômico, não tem demonstrado eficiência em relação a políticas públicas necessárias para estabilizar o mercado de trabalho, diminuindo a informalidade, assegurando as vagas existentes evitando assim o desemprego em massa.

A falta de empenho para ordenar a entrada e saída de trabalhadores do mercado, evitando a rotatividade é reforçada por Baltar (2014), que evidencia o desrespeito da legislação trabalhista e instabilidade nos vínculos empregatícios, considerando elevada a taxa de desemprego existente no país. No entanto, para o autor, a propensão de aumento do emprego formal assegurada por alguns indicadores pode ser atribuída à formalização de empreendimentos que, de modo geral, está sujeito ao crescimento do PIB. Entretanto, atribui a sazonalidade na movimentação temporária nos postos de trabalho a mudanças estruturais na economia.

No tocante ao disposto, em recente pesquisa, utilizando dados dos últimos 30 anos da Pesquisa de Emprego e Desemprego (PED), na Região Metropolitana de São Paulo (RMSP), Garcia e Gonzaga (2014) retrataram a evolução do desemprego, o perfil do desempregado e a formalização dos contratos de trabalho nesta região. Os resultados explicitaram que, na RMSP, a taxa total de desemprego teve picos na década de 1990, período de austeridade fiscal no país, decaindo somente a partir de 2002. Destacaram ainda que, no período avaliado, a ocorrência da diminuição do espaço no mercado de trabalho por parte dos mais jovens, enquanto as mulheres ganharam mais espaço. Por conseguinte, em relação ao assalariamento, a formalização dos contratos de trabalho foi ampliada igualmente a partir de 2002 .

Analogamente, em estudo realizado no estado do Rio Grande do Sul, Stein, Sulzbach e Bartels $(2015$, p.28) abordaram a questão da formalidade relacionada diretamente ao salário no estado e concluíram que: "quanto maior for o piso regional em relação ao salário mínimo nacional, maior será seu impacto na redução do tamanho do setor formal do mercado de trabalho". Desse modo, pode-se afirmar que a formalidade no Rio Grande do Sul está fortemente associada ao valor que o empregado recebe, o que aparentemente configura o aumento ou redução dos postos formais de trabalho. Os autores colocam ainda que, quanto maior for o salário ofertado, maior o índice de formalidade; nesse 
sentido, analogamente, os setores com maior número de desligamentos formais, e consequentemente maior número de empregados celetistas, podem ser considerados os setores que ofertam maiores salários aos seus trabalhadores. Tal explicação se dá ao fato de que, um emprego formal obrigatoriamente precisa ofertar o piso da categoria, caso contrário, um salário menor não comportará os requisitos da formalidade.

Utilizando-se de outra base dados, da Pesquisa Mensal de Emprego (PME), realizada em regiões metropolitanas, no Brasil, Monte, Júnior e Pereira (2009) analisaram um contexto diferente: a influência do tempo do desemprego no salário recebido pelo trabalhador em sua reinserção no mercado de trabalho. Os resultados constataram perda salarial em sua recontratação e pessoas com ensino médio e superior e com idade entre 31 e 40 anos são as mais prejudicadas em virtude de exigências ao tipo de ocupação e rendimentos maiores esperados.

Nesse sentido, Carvalho (2011) realizou um estudo em todas as regiões metropolitanas também com base de dados da PED e analisou o cenário entre 1997/1998 e 2007. Considerando apenas a Região Metropolitana de Porto Alegre (RMPA), a autora constatou um decréscimo em torno de $26 \%$ nos postos de trabalho na década de 1990, o que atribuiu, principalmente, ao fato da transferência de empresas para outras regiões do país em busca por incentivos fiscais e mão de obra mais barata.

Entre 1997/98 e 2007, na RMPA, a população economicamente ativa cresceu em torno de $29,2 \%$, enquanto os ocupados, nesse período, em todos os setores de atividade econômica, diminuíram apenas o setor de serviços ampliou a ocupação em 3\%. Os assalariados com carteira assinada aumentaram em apenas $1 \%$ enquanto os ocupados na informalidade aumentaram em $3 \%$. A taxa de desemprego aberto igualmente aumentou em $0,1 \%$ e, a estimativa de rendimento médio dos assalariados, em reais diminuiu de 1.202 em 1997/1998 para 1.036 em 2007. Ainda, a estimativa de queda do rendimento real médio dos ocupados foi maior em indivíduos com ensino médio completo, com $31 \%$ de queda, o que também foi encontrado por Monte, Júnior e Pereira (2009).

De modo semelhante, os resultados deste artigo evidenciaram um crescimento gradativo na eliminação dos empregos formais no estado do Rio Grande do Sul. Certamente diferentes indicadores, sejam sociais, econômicos ou políticos impactam nessa esfera.

Tal situação pode ser considerada crítica, uma vez que os dados mostram expectativas adversas e continuidade do quadro apresentado por Carvalho (2011), levando a desigualdades sociais e impactos desfavoráveis à economia do estado do Rio Grande do Sul.

Em suma, essa realidade é reflexo da administração política, econômica e social, pois o desemprego em todos os setores está relacionado a inúmeros fatores que produziriam outro estudo mais aprofundado. Contudo, o aumento esperado nos desligamentos do emprego formal no Rio Grande do Sul provoca 
angústia em relação ao futuro próximo e, como diz Accurso (2002, p.21), é constrangedor saber que o estado não dirige o caixa e sim "o caixa que dirige o estado”, sem perspectivas de mudança coerentes e positivas.

\section{Considerações finais}

A estimativa de aumento no desligamento de indivíduos em emprego formal em todos os setores de atividade econômica no Rio Grande do Sul é muito mais complexa do que é exposto neste estudo, pois essa informação não está dissociada de tantos outros fatores que afetam a evolução do mercado de trabalho. Ajustes fiscais, salário mínimo, aumento da população, relações econômicas internas e externas, preço do câmbio, relações politicas, entre outros, interferem diretamente na oferta de postos de trabalho, formalidade dos contratos e desligamentos ou diminuição de vagas de emprego.

Falar em crise como justificativa da situação austera e desconsolada vigente tornou-se corriqueiro em dias atuais, entretanto o apontamento de soluções sólidas e concretas por parte daqueles que se ofereceram politicamente para governar e controlar a realidade do estado escassamente é presenciada. Mudanças drásticas e superficiais devem ser analisadas com rigor, no intuito de evitar o insucesso ou regresso de avanços já alcançados.

Nessa perspectiva, a esperança prevalece no sentido de que autoridades competentes intervenham de forma substancial com a finalidade de minimizar os efeitos negativos da situação crítica presente no mercado de trabalho do RS, evitando assim a instabilidade e evacuação em massa de indivíduos empregados em todos os setores da economia.

Sendo assim, a redução do desemprego auxiliará na erradicação da desigualdade social, pois, em um estado que historicamente é coadjuvante no crescimento brasileiro, a promoção de iniciativas estratégicas é fundamental para a efetivação de um desenvolvimento próspero.

\section{Referências}

ACCURSO, C. Estratégias de desenvolvimento para o Rio Grande do Sul. Ensaios FEE, Porto Alegre, v.23, n. esp., 2002.

ANTUNES, R. A crise, o desemprego e alguns desafios atuais. Serviço Social e Sociedade, n.104, p.632-36, out./dez. 2010. Disponível em: <http://dx.doi.org/10.1590/ S0101-66282010000400003>. Acesso em: 20 jun. 2015.

BALTAR, P. Política econômica, emprego e política de emprego no Brasil. Estudos Avançados, São Paulo, v.28, n.81, ago. 2014. Disponível em: <http://dx.doi.org/10.1590/ S0103-40142014000200007>. Acesso em: 10 jun. 2015.

CAGED. Cadastro Geral de Emprego e Desemprego. Dados estatísticos. Ministério do Trabalho e Emprego. 2015. Disponível em: <http://portal.mte.gov.br/caged/>. Acesso em: 10 jun. 2015. 
CARVALHO, I. M. M. Mercado de trabalho e vulnerabilidade em regiões metropolitanas brasileiras. Caderno Crh, Salvador, v.24, n.62, p.397-412, maio/ago. 2011. Disponível em: <http://www.scielo.br/pdf/ccrh/v24n62/allv24n62.pdf>. Acesso em: 12 jun. 2015.

GARCIA, L.; GONZAGA, L. L. Pesquisa de emprego e desemprego: trinta anos de acompanhamento do mercado de trabalho na Região Metropolitana de São Paulo. Estudos Avançados, São Paulo, v.28, n.81, maio/ago. 2014. Disponível em: <http:// dx.doi.org/10.1590/S0103-40142014000200009>. Acesso em: 25 nov. 2014.

HOFF, C. R.; LAZZARI, M. R. Desenvolvimento econômico no Rio Grande do Sul. Org. Ely José de Mattos e Izete Pengo Bagolin. Porto Alegre: Edipucrs, 2014.

JORNADA, M. I. H. O mercado de trabalho no Rio Grande do Sul e o Plano Real: principais evidências. Indic. Econ. FEE, Porto Alegre, v.32, n.2, p.223-46, ago. 2004.

MONTE, P. A.; JÚNIOR, I. T. A.; PEREIRA, M. L. O custo salarial da duração do desemprego para o trabalhador. Nova Economia, Belo Horizonte, v.19, n.13, p.443-70, set./dez. 2009.

STEIN, G.; SULZBACH, V. N.; BARTELS, M. Relatório sobre o mercado de trabalho do Rio Grande do Sul - 2001-13. Porto Alegre: FEE, 2015.

RESUMO - Esta pesquisa tem por objetivo analisar o número mensal de desligamentos do emprego formal, por setor de atividade, de janeiro de 2004 a dezembro de 2014, no Rio Grande do Sul. Foi realizada uma análise descritiva, comparando-se o número de desligamentos e as diferenças entre dois períodos. Foi utilizada regressão simples para avaliar a ocorrência ou não de tendências significativas. Foram eliminados, no RS, 12.404.198 empregos celetistas no período considerado, sendo Indústria de Transformação o setor com maior número de desligamentos (3.813.805) e Extrativa Mineral com menor valor (25.490). Os resultados permitem concluir que o Rio Grande do sul apresentou valores elevados nos desligamentos, com tendência crescente significativa em sete dos oito setores considerados.

PALAVRAS-CHAVE: Evolução do desemprego, Setor de atividade econômica, Previsão, Rio Grande do Sul.

ABSTRACT - This research aims to analyze the monthly number of job dismissals by industry, from January 2004 to December 2014, in the state of Rio Grande do Sul. A descriptive analysis was performed comparing the number of job dismissals and the differences between the two periods. A simple regression was used to assess the presence or absence of significant trends. In Rio Grande do Sul, a total of 12,404,198 formal jobs were eliminated over the period in question. Manufacturing had the highest number of dismissals $(3,813,805)$ and mineral extraction the lowest $(25.490)$. The results 
show that Rio Grande do Sul had a high rate of dismissals, with a significant growing trend in seven out of the eight industries analyzed.

KEYWORDS: Evolution of unemployment, Sector of economic activity, Forecasting, Rio Grande do Sul.

Juliana Haetinger Furtado é licenciada em Matemática pela Universidade Regional Integrada do Alto Uruguai e das Missões e estudante de mestrado do Programa de PósGraduação em Engenharia de Produção da Universidade Federal de Santa Maria (RS). @ - julihfurtado21@hotmail.com

Adriano Mendonça Souza é professor associado do Departamento de Estatística e atua no Programa de Pós-Graduação em Engenharia de Produção da Universidade Federal de Santa Maria (RS). @- amsouza.sm@gmail.com

Roselaine Ruviaro Zanini é professora associada do Departamento de Estatística e atua no Programa de Pós-Graduação em Engenharia de Produção da Universidade Federal de Santa Maria (RS). @-rrzanini63@gmail.com

Recebido em 25.8.2015 e aceito em 21.9.2015.

I, II, III Universidade Federal de Santa Maria, Santa Maria/Rio Grande do Sul, Brasil. 
